Dalia L. Rotstein, MD

Brian C. Healy, PhD

Muhammad T. Malik, MD

Robert L. Carruthers, MD

Alexander J. Musallam, MSc

Pia Kivisakk, MD, PhD

Howard L. Weiner, MD

Bonnie Glanz, PhD

Tanuja Chitnis, MD

Correspondence to

Dr. Chitnis:

tchitnis@partners.org
Supplemental data at Neurology.org/nn

\title{
Effect of vitamin D on MS activity by disease-modifying therapy class
}

OPEN

ABSTRACT

Objective: To determine whether vitamin $D$ status predicts disease activity in patients with multiple sclerosis (MS) taking interferon- $\beta$ (IFN), glatiramer acetate (GA), and fingolimod (FTY).

Methods: Participants ( $n=324$ ) with relapsing-remitting MS on IFN (96), GA (151), or FTY (77) were identified from the Comprehensive Longitudinal Investigation of MS at Brigham and Women's Hospital (CLIMB) Study at the Partners MS Center. FTY-treated participants were analyzed separately because of differences in selection. Serum vitamin 25(OH)D concentration was adjusted for season. We evaluated the relationship between $25(\mathrm{OH}) \mathrm{D}$ tertile and time to relapse or gadolinium-enhancing lesion using a Cox model adjusted for age, sex, and disease duration.

Results: Higher 25(OH)D was associated with longer time to the combined endpoint in the overall IFN/GA cohort ( $p$ for trend $=0.042$; hazard ratio $[H R]=0.77$ ) and in the IFN subgroup $\left(H R_{\text {IFN }}=\right.$ 0.58 ; $\left.p_{\text {IFN }}=0.012\right)$, but not in GA-treated participants $(p=0.50 ; \mathrm{HR}=0.89)$. For gadoliniumenhancing lesions alone, there was a significant association observed in GA and IFN subgroups, although the effect was more pronounced on IFN $\left(\mathrm{HR}_{\mathrm{GA}}=0.57 ; \mathrm{p}_{\mathrm{GA}}=0.039 \mathrm{vs} \mathrm{HR}_{\mathrm{IFN}}=0.41\right.$; $\left.\mathrm{P}_{\mathrm{IFN}}=0.022\right)$. No significant associations were found for relapses. For FTY, higher 25(OH)D was associated with longer survival for the combined endpoint $\left(\mathrm{HR}_{\mathrm{FTY}}=0.48 ; p_{\mathrm{FTY}}=0.016\right)$ and for relapses $\left(\mathrm{HR}_{\mathrm{FTY}}=0.50 ; p_{\mathrm{FTY}}=0.046\right)$, but not for gadolinium-enhancing lesions.

Conclusions: Disease activity generally improved with higher $25(\mathrm{OH}) \mathrm{D}$, but this study raises the question of effect modification by treatment class. Neurol Neuroimmunol Neuroinflamm 2015;2: e167; doi: 10.1212/NXI.0000000000000167

\section{GLOSSARY}

CLIMB = Comprehensive Longitudinal Investigation of Multiple Sclerosis at Brigham and Women's Hospital; COV = coefficient of variation; DMT = disease-modifying therapy; EDSS = Expanded Disability Status Scale; FTY = fingolimod; GA = glatiramer acetate; $\mathbf{G d +}$ = gadolinium-enhancing; HR = hazard ratio; IFN = interferon; $\mathbf{M S}$ = multiple sclerosis; $\mathbf{R R M S}=$ relapsing-remitting multiple sclerosis.

Vitamin D deficiency has been associated with increased disease activity in established relapsingremitting multiple sclerosis (RRMS). ${ }^{1-7}$ Protective effects of vitamin D are thought to be related to its immunomodulatory properties, including inhibiting dendritic cell differentiation and $\mathrm{T}_{\mathrm{H}} 1$ and $\mathrm{T}_{\mathrm{H}} 17$ cell responses. ${ }^{8,9}$ Disease-modifying therapies (DMTs) in multiple sclerosis (MS) have some of the same properties, although they vary with class of drug. To date, the effect of vitamin $\mathrm{D}$ has been studied in patients treated with interferon (IFN) $-\beta^{4,5,7,10-12}$ or where treatment was undifferentiated. ${ }^{6,13}$ It is unknown whether increased vitamin D status may exert the same protective effect in the majority of patients with MS treated with DMTs other than interferons. We set out to determine the effect of vitamin D status on clinical and MRI outcomes in patients with MS treated with IFN, glatiramer acetate (GA), and fingolimod (FTY).

METHODS Participants. Three groups of participants contributed to the analysis; all were enrolled from the Comprehensive Longitudinal Investigation of Multiple Sclerosis at Brigham and Women's Hospital (CLIMB), a prospective cohort study that began

From the Partners Multiple Sclerosis Center (D.L.R., B.C.H., M.T.M., R.L.C., A.J.M., H.L.W., B.G., T.C.) and Ann Romney Center for Neurologic Diseases (P.K., H.L.W., T.C.), Brigham and Women's Hospital; and Biostatistics Center (B.C.H.), Massachusetts General Hospital, Boston.

Funding information and disclosures are provided at the end of the article. Go to Neurology.org/nn for full disclosure forms. The Article Processing Charge was paid by Brigham and Women's Hospital.

This is an open access article distributed under the terms of the Creative Commons Attribution-NonCommercial-NoDerivatives License 4.0 (CC BY-NC-ND), which permits downloading and sharing the work provided it is properly cited. The work cannot be changed in any way or used commercially. 
enrolling participants in 2000. ${ }^{14}$ Participants in CLIMB have a clinical visit with complete neurologic examination every 6 months, including the Expanded Disability Status Scale (EDSS), and brain MRI scan every 12 months. All participants were age $18-65$ years, EDSS $<5$, with a diagnosis of RRMS based on McDonald 2005 criteria. ${ }^{15}$ The first 2 groups consisted of participants treated with GA or IFN as their initial DMT. The latter included patients on IM IFN- $\beta$-1a weekly (Avonex; Biogen, Cambridge, MA), subcutaneous IFN- $\beta-1$ a TIW (Rebif; Merck Serono, Darmstadt, German), and subcutaneous IFN$\beta$-1b QOD (Betaseron; Bayer HealthCare Pharmaceuticals, Whippany, NJ). Each participant was required to be on monotherapy and have a blood draw within 18 months of treatment onset. The third group consisted of participants on FTY monotherapy. All patients initiating FTY and participating in research at our Center were asked to have a blood draw at the time of their first-dose observation. For participants in all 3 treatment groups, a second blood sample was analyzed where available on the same treatment within 3-18 months after the first. Demographic characteristics of the 3 groups are shown in table 1 . We decided at the outset to analyze the FTY-treated cohort separately from the IFN- and GA-treated groups because most FTY participants had previously been treated with other agents and because of the differences in blood sample collection.

Standard protocol approvals, registrations, and patient consents. The CLIMB study was approved by the Institutional Review Board at the Brigham and Women's Hospital. All participants provided written informed consent.

Vitamin D level measurement. The 25-hydroxyvitamin D $(25[\mathrm{OH}] \mathrm{D})$ concentration was measured from serum samples using a chemiluminescent microparticle assay (ARCHITECT from Abbott Laboratories) at Harvard Catalyst Laboratory, Massachusetts General Hospital. The intra-assay coefficient of variation $(\mathrm{COV})$ has been reported as $2.6 \%-4.6 \%$. Interassay $\mathrm{COV}$ was not available. Serum samples were stored at $-80^{\circ} \mathrm{C}$ before use. Testing was conducted in 3 batches: 2 consisting of FTY participants and a final batch including all samples from GA- and IFN-treated participants. The 25(OH)D level was measured in $\mathrm{ng} / \mathrm{mL}(1 \mathrm{ng} / \mathrm{mL}=2.496 \mathrm{nmol} / \mathrm{L})$.
The $25(\mathrm{OH}) \mathrm{D}$ was adjusted for seasonal variation using a standard model for day of the year (see appendix e-1 at Neurology.org/nn for further details).

Clinical/radiologic outcome measures. Our primary outcome measure was development of a relapse or new T1 gadoliniumenhancing $(\mathrm{Gd}+)$ lesion on MRI. Relapse was defined as the appearance of new symptoms lasting more than 24 hours in the absence of fever or intercurrent illness and was determined by the treating physician at the biannual clinical visit. ${ }^{16}$ Appearance of new Gd+ MRI lesions was based on the neuroradiologist's report. Other secondary outcome measures were relapses alone and disability progression, as defined by an increase of at least 1 for participants with a baseline EDSS between 1 and 5, or at least 1.5 for participants with a baseline EDSS of 0 . Progression was not required to be sustained because of limited duration of follow-up.

Statistical analysis. IFN/GA group. We used survival analysis to explore time from the first $25(\mathrm{OH}) \mathrm{D}$ level to the various outcome measures of interest. In the primary analysis, we investigated time to first inflammatory event, defined as time to first relapse or Gd+ lesion on brain MRI. In the secondary analyses, we investigated time to first relapse alone, first $\mathrm{Gd}+$ lesion alone, or disability progression. Additional details are provided in appendix e-1.

FTY group. Baseline clinical and demographic characteristics of the FTY cohort are shown in table 1, but were not compared with the IFN/GA cohort because selection was not limited to those on their first DMT. We conducted the same analyses as in the IFN/GA cohort, except that events within 30 days after the first 25(OH)D measurement were excluded since all participants had their first $25(\mathrm{OH}) \mathrm{D}$ measurement on the day of FTY initiation, and FTY is known to take at least 30 days before its effects are observed. ${ }^{17}$ Cox proportional hazards models were adjusted for age, disease duration, and sex as in the IFN/GA group; however, we did not adjust for the year of treatment initiation because FTY was only available during 2 of the years studied.

Sensitivity analyses. See appendix e-1.

RESULTS IFN/GA cohort. A total of 247 participants met inclusion criteria: 151 on GA and 96 on IFN

Table 1 Baseline clinical and demographic characteristics of all 3 treatment groups

\begin{tabular}{|c|c|c|c|}
\hline & IFN & GA & FTY \\
\hline No. & 96 & 151 & 77 \\
\hline Female, n (\%) & 66 (68.7) & 105 (69.5) & 60 (77.9) \\
\hline White, $\mathrm{n}(\%)$ & 91 (94.8) & $140(93.3)$ & 67 (90.5) \\
\hline Hispanic, n (\%) & $4(4.2)$ & 5 (3.3) & $7(9.1)$ \\
\hline Age at first vitamin $D$ measurement, $y$, mean (SD) & $38.9(9.5)$ & $39.2(9.7)$ & $40.8(9.8)$ \\
\hline $\begin{array}{l}\text { Disease duration at first vitamin } D \\
\text { measurement, } y \text {, mean (SD) }\end{array}$ & $3.3(3.6)^{\mathrm{a}}$ & $4.5(4.6)$ & $9.2(4.7)$ \\
\hline EDSS at first vitamin D measurement, median (IQR) & $1(0-2)^{a}$ & $1(0-1.75)$ & $1.5(0.75-2.5)$ \\
\hline $\begin{array}{l}\text { Time from treatment initiation to first } \\
\text { vitamin } D \text { measurement, } y \text {, mean (SD) }\end{array}$ & $0.724(0.412)$ & $0.746(0.449)$ & $0(0)$ \\
\hline Follow-up interval, $y$, mean (SD) & $4.5(3.4)$ & 4.2 (3.0) & $1.6(0.6)$ \\
\hline 25(OH) D level, ng/mL & 24.9 (11.9) & $27.5(13.0)$ & 30.8 (13.3) \\
\hline Two 25(OH) D measurements, $n$ (\%) & $56(58)$ & $94(62)$ & $73(95)$ \\
\hline Supplementation at first measurement, $\mathrm{n}(\%)$ & $31(32.6)^{a}$ & $83(55.7)$ & $50(64.9)$ \\
\hline
\end{tabular}

Abbreviations: EDSS = Expanded Disability Status Scale; FTY = fingolimod; GA = glatiramer acetate; IFN = interferon . a Significant difference from the GA group as indicated by $p<0.05$. 
(table 1). Baseline demographic characteristics were typical of early RRMS. Differences in disease duration $(p=0.014)$ and EDSS $(p=0.046)$ were observed, but the magnitude of these differences was minor. Duration of follow-up was similar in both groups: 4.2 years for GA and 4.5 years for IFN. The share with 2 25(OH)D measurements available was comparable, ranging from $58 \%$ to $62 \%(p=0.593$ ). There was no significant difference in absolute or seasonally adjusted $25(\mathrm{OH}) \mathrm{D}$ levels at baseline, although the rate of vitamin $\mathrm{D}$ supplementation was greater in the GA group (56\% vs 33\%; $p=0.0007$ ).

The effects of vitamin D on the hazard of events in the overall cohort and individual treatment groups are provided in table 2, and the corresponding KaplanMeier curves in figure 1 , figures e-1 and e-2. In the overall cohort, there was a decrease of approximately $25 \%$ in the hazard of relapse or $\mathrm{Gd}+$ lesion with each tertile increase in $25(\mathrm{OH}) \mathrm{D}$ in both unadjusted and adjusted Cox models (table 2, figure 1A). In the IFN treatment group, there was a greater decrease of approximately $40 \%$ with each higher $25(\mathrm{OH}) \mathrm{D}$ tertile (table 2, figure e-1A). However, in the GA treatment group, there was no significant association between $25(\mathrm{OH}) \mathrm{D}$ level and event hazard (table 2, figure e-2A). In the GA group, there was evidence of a potential departure from proportional hazards for the $25(\mathrm{OH}) \mathrm{D}$ tertiles $(p=0.067$ for test of Schoenfeld residuals in adjusted model). The lack of proportional hazards is also shown through the crossing survival curves. No significant interaction between 25(OH)D tertile and treatment was observed (table 2).

There was no statistically significant change in hazard of relapse with higher $25(\mathrm{OH}) \mathrm{D}$ levels in the combined cohort or either individual treatment group (figure 1B, figures e-1B and e-2B). A significant departure from proportional hazards was observed in the GA group ( $p=0.020$ for test of Schoenfeld residuals). Conversely, there was significant improvement in new $\mathrm{Gd}+$ lesions with higher 25(OH)D levels in both treatment groups (figure $1 \mathrm{C}$, figures e-1C, and e-2C). Hazard reduction was greater in the IFN group, where there was a $59 \%$ decrease in the hazard of new active MRI lesions per $25(\mathrm{OH}) \mathrm{D}$ tertile, compared to $43 \%$ in the GA group. In the combined cohort, there was a $53 \%$ decrease. There was no statistically significant change in disability progression with vitamin $\mathrm{D}$ status (figure 1D, figures e-1D and e-2D). No significant interaction between $25(\mathrm{OH}) \mathrm{D}$ tertile and treatment was observed for any outcome measure (table 2).

Sensitivity analyses. When analyses were repeated using only the first $25(\mathrm{OH}) \mathrm{D}$ measurement as the predictor, there was no appreciable change in results, although they became slightly less significant. For example, in the primary analysis examining time to first inflammatory event, the hazard ratio (HR) in the overall cohort was $0.82(p=0.12)$ and the HR in the IFN group was $0.66(p=0.046)$. Trends across the treatment groups remained the same, with the GA group demonstrating less of a benefit from vitamin $\mathrm{D}$ for each outcome measure. When vitamin D status was treated as a continuous variable, results were again consistent (table e-1).

The results likewise remained stable with addition of vitamin D supplementation as either a dichotomous covariate at baseline or time-varying covariate. In the primary analysis, the first approach led to

Table 2 Association between 25(OH)D tertiles and time to event in the IFN/GA cohort

\begin{tabular}{|c|c|c|c|c|}
\hline & IFN/GA & IFN & GA & $\begin{array}{l}\text { Interaction } \\
\text { p Value }\end{array}$ \\
\hline \multicolumn{5}{|c|}{ Time to first inflammatory event } \\
\hline Unadjusted HR (95\% Cl) & $0.73(0.57-0.93)^{a}$ & $0.62(0.40-0.95)^{a}$ & $0.81(0.60-1.10)$ & 0.30 \\
\hline Adjusted HR (95\% Cl) & $0.77(0.59-0.99)^{a}$ & $0.58(0.38-0.89)^{a}$ & $0.89(0.63-1.25)$ & 0.14 \\
\hline \multicolumn{5}{|l|}{ Time to first relapse } \\
\hline Unadjusted HR (95\% CI) & $0.81(0.61-1.08)$ & $0.73(0.45-1.18)$ & $0.89(0.62-1.27)$ & 0.53 \\
\hline Adjusted HR (95\% Cl) & $0.86(0.64-1.16)$ & $0.66(0.41-1.09)$ & $0.92(0.61-1.38)$ & 0.31 \\
\hline \multicolumn{5}{|l|}{ Time to first Gd+ lesion } \\
\hline Unadjusted HR (95\% Cl) & $0.49(0.33-0.75)^{\mathrm{a}}$ & $0.42(0.20-0.88)^{a}$ & $0.55(0.34-0.91)^{a}$ & 0.52 \\
\hline Adjusted HR (95\% Cl) & $0.47(0.31-0.73)^{a}$ & $0.41(0.19-0.88)^{a}$ & $0.57(0.34-0.97)^{a}$ & 0.40 \\
\hline \multicolumn{5}{|c|}{ Time to first EDSS progression } \\
\hline Unadjusted HR (95\% Cl) & $1.17(0.87-1.57)$ & $0.88(0.53-1.45)$ & 1.39 (0.96-2.02) & 0.19 \\
\hline Adjusted HR (95\% Cl) & $1.24(0.90-1.72)$ & $0.99(0.58-1.69)$ & 1.50 (0.97-2.32) & 0.23 \\
\hline
\end{tabular}

Abbreviations: $\mathrm{Cl}=$ confidence interval; EDSS $=$ Expanded Disability Status Scale; GA = glatiramer acetate; Gd $+=$ gadolinium-enhancing; $\mathrm{HR}$ = hazard ratio; IFN = interferon.

${ }^{\text {a }}$ Significant effect as indicated by $p<0.05$. 
A

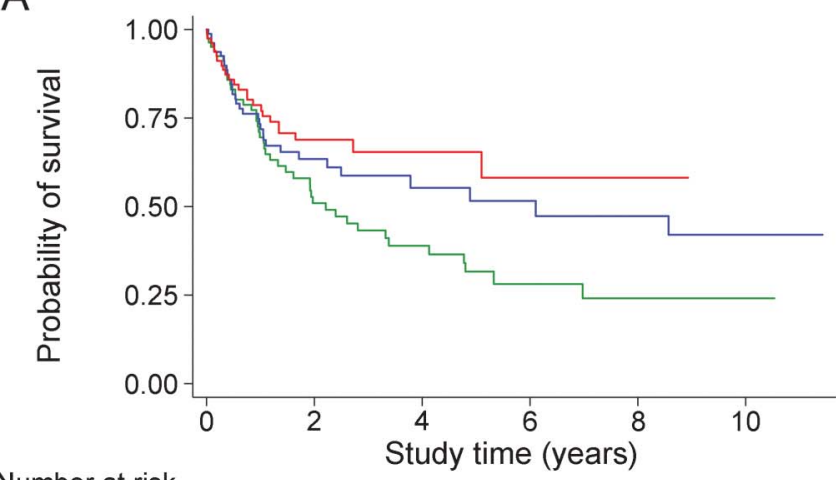

Number at risk Bottom 82

Middle 79

Top 82

C

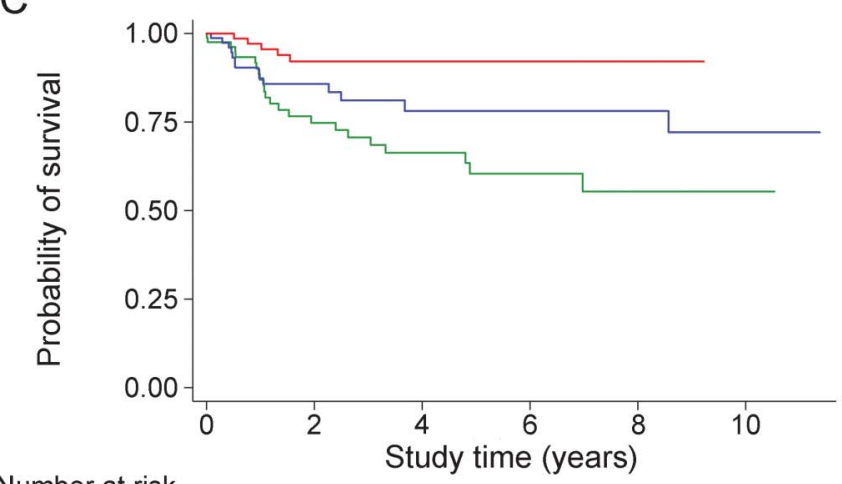

B

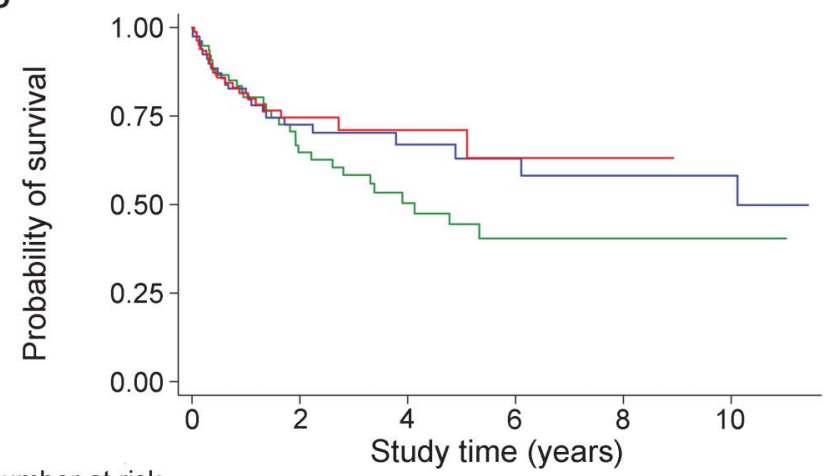

Number at risk

Bottom 81

Middle 79

Top 82

$\mathrm{D}$

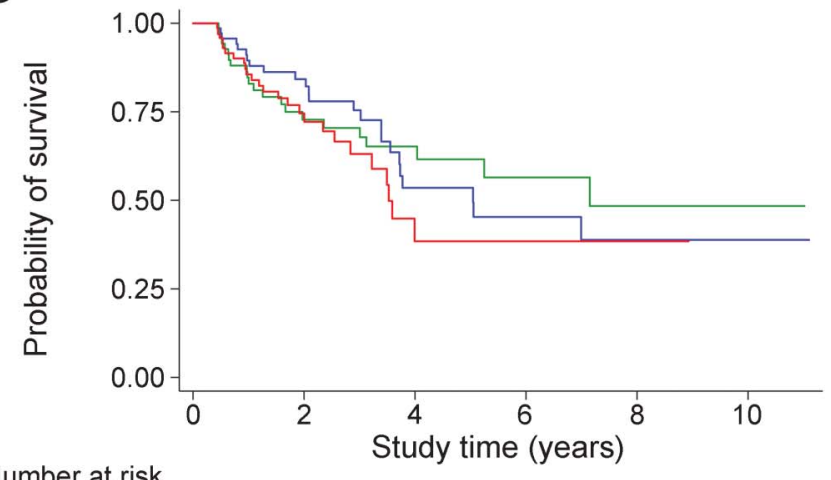

Number at risk

$\begin{array}{rccccc}\text { Bottom } 81 & 33 & 18 & 10 & 6 & 3 \\ \text { Middle 78 } & 42 & 15 & 9 & 6 & 3 \\ \text { Top 82 } & 31 & 6 & 4 & 2 & 0\end{array}$

In each graph, bottom tertile: solid line; middle tertile: long dashed line; top tertile: short dashed line. (A) Time to first inflammatory event (relapse or gadolinium-enhancing lesion). (B) Time to first relapse. (C) Time to first gadolinium-enhancing lesion. (D) Time to first Expanded Disability Status Scale progression.

$\mathrm{HR}=0.76(p=0.044)$ for the overall cohort. Using the second approach of treating vitamin D supplementation as a time-varying covariate, $\mathrm{HR}$ was 0.75 $(p=0.036)$.

FTY cohort. A total of 77 participants initiating FTY were included with mean follow-up of 1.6 years (table 1). FTY participants were older, with longer disease duration and higher baseline EDSS; these findings reflect use of FTY as a second-line therapy. A second blood sample was available for 73 (95\%).

Effects of $25(\mathrm{OH}) \mathrm{D}$ on the hazard of event are provided in table 3, and the corresponding KaplanMeier curves in figure 2. A significant association was observed between $25(\mathrm{OH}) \mathrm{D}$ tertile and time to first inflammatory event in both unadjusted and adjusted analyses. For time to next relapse, a significant association was observed in the adjusted analysis. For time to first Gd+ lesion or EDSS progression, there was no significant association between $25(\mathrm{OH}) \mathrm{D}$ level and time to event.
Sensitivity analyses. When analyses were repeated using only first $25(\mathrm{OH}) \mathrm{D}$ measurement as the predictor, the impact of $25(\mathrm{OH}) \mathrm{D}$ tertile was smaller, and there was no significant effect. When $25(\mathrm{OH}) \mathrm{D}$ level was treated as a continuous variable, results were similar to the primary analysis. Finally, when vitamin D supplementation was included in the model, results remained the same as above.

DISCUSSION In this study, we took the approach of examining the effect of vitamin D in MS on DMTs other than IFN. We found that higher $25(\mathrm{OH}) \mathrm{D}$ levels conferred a significant protective benefit against new inflammatory events (relapses or Gd+ lesions) in participants treated with IFN, with an effect magnitude similar to what has been reported in previous studies of a $30 \%-50 \%$ reduction in event rate per 10 $\mathrm{ng} / \mathrm{mL}$ increase in $25(\mathrm{OH}) \mathrm{D}$ level. ${ }^{4,5,10}$ There was no significant benefit of higher $25(\mathrm{OH}) \mathrm{D}$ levels with respect to inflammatory events, relapses, or disability progression in the GA group; there was a significant, 


\begin{tabular}{|c|c|}
\hline Table 3 & $\begin{array}{l}\text { Association between vitamin } D \text { tertiles } \\
\text { and time to event in the fingolimod } \\
\text { cohort }\end{array}$ \\
\hline & HR (95\% Cl) \\
\hline \multicolumn{2}{|c|}{ Time to first inflammatory event } \\
\hline \multicolumn{2}{|l|}{ Unadjusted } \\
\hline \multicolumn{2}{|l|}{ Adjusted } \\
\hline \multicolumn{2}{|c|}{ Time to first relapse } \\
\hline \multicolumn{2}{|l|}{ Unadjusted } \\
\hline \multicolumn{2}{|l|}{ Adjusted } \\
\hline \multicolumn{2}{|c|}{ Time to first Gd+ lesion } \\
\hline \multicolumn{2}{|l|}{ Unadjusted } \\
\hline \multicolumn{2}{|l|}{ Adjusted } \\
\hline \multicolumn{2}{|c|}{ Time to first EDSS progression } \\
\hline Unadjusted & $0.82(0.39-1.74)$ \\
\hline Adjusted & $0.80(0.36-1.76)$ \\
\hline
\end{tabular}

Abbreviations: $\mathrm{Cl}=$ confidence interval; EDSS = Expanded Disability Status Scale; Gd+ = gadolinium-enhancing; HR = hazard ratio.

a Significant effect as indicated by $p<0.05$.

but lesser, protective effect against active MRI lesions alone in the GA group compared to the IFN group. While there were differences in several baseline characteristics between the GA and IFN treatment groups, multivariate adjustment accentuated the gap between the HRs associated with each. However, we should still interpret comparison of the treatment groups with caution because there may have been unmeasured confounders of patient selection for treatment. In the FTY group, which was analyzed separately, we observed an approximately $50 \%$ reduction in new inflammatory events and in relapses alone per $25(\mathrm{OH}) \mathrm{D}$ tertile increase. Controlling for vitamin D supplementation did not meaningfully alter results in any of the treatment groups.

At the same time, we cannot conclude that the effect of vitamin D in MS is modified by DMT class because there was no statistically significant $(p<$ $0.05)$ interaction when a $25(\mathrm{OH}) \mathrm{D}^{*}$ treatment term was included in our models. Moreover, there was evidence of a departure from the proportional hazards assumption in the GA group, which can lead to inaccurate estimation of the effect size based on the Cox model. In particular, assessment of Kaplan-Meier curves in the GA group showed that the hazard in the high $25(\mathrm{OH}) \mathrm{D}$ tertile was the highest initially, but then it became the lowest after the initial phase. Thus the lack of significant findings in some of the analyses in the GA group does not necessarily indicate that vitamin D has no effect. The question of whether the protective effect of vitamin D on MS disease activity may be weaker in participants treated with GA as compared to IFN needs to be explored in other cohorts before leading to any change in recommendations around vitamin D supplementation. An earlier cohort study reported that higher $25(\mathrm{OH}) \mathrm{D}$ was protective in participants on IFN but not in controls on GA, mitoxantrone, or no therapy, but the control group was small $(\mathrm{n}=46) .{ }^{10}$ There is an ongoing randomized controlled trial of vitamin $\mathrm{D}$ supplementation on GA, Vitamin D to Ameliorate Multiple Sclerosis (VIDAMS), which should assist in clarifying whether improved vitamin D status may indeed ameliorate MS disease activity on GA. ${ }^{18}$ On the other hand, given the lack of a second DMT comparator group, this study will provide no direct information about potential effect modification.

$25(\mathrm{OH}) \mathrm{D}$ levels were higher in the FTY compared to the IFN/GA cohort, which may be due to greater prevalence of supplementation and higher recommended doses in recent years. In the FTY group, we observed a $50 \%$ reduction in the event hazard with higher 25(OH)D levels, despite FTY's independent profound immunomodulatory properties and superior suppression of disease activity rates, at least relative to IM IFN- $\beta-1 a{ }^{18}$ We cannot directly compare this result to event reduction in the IFN/GA group due to restriction of the IFN/GA cohort to participants on first-line therapy and the difference in blood sample collection times relative to treatment initiation. However, it is reasonable to conclude from this effect size that the influence of vitamin D on FTY is relatively comparable to what has been observed in previously untreated or IFN-treated patients with MS.

One possible explanation for differences in efficacy across treatment groups may be related to immunologic mechanisms of each of the treatments and vitamin D. Vitamin D's diverse immunologic functions include inhibiting monocytes, activating T-regulatory cell differentiation, and shifting $\mathrm{T}_{\mathrm{H}} 1$ to $\mathrm{T}_{\mathrm{H}} 2$ cellular responses. ${ }^{8,9,19-21}$ FTY's mechanism of action is distinct, as it acts on the peripheral immune system to sequester T-lymphocytes in the lymph nodes, thus reducing $\mathrm{T}$-cell trafficking into the $\mathrm{CNS}{ }^{22}$ IFN, like vitamin $\mathrm{D}$, promotes $\mathrm{T}_{\mathrm{H}} 2$ over $\mathrm{T}_{\mathrm{H}} 1$ responses, but does not affect monocytes or T-regulatory cells to a meaningful extent. ${ }^{23,24}$ In contrast, GA shares each of these immune mechanisms with vitamin D. Thus, the immunomodulatory actions of FTY and IFN relative to vitamin $\mathrm{D}$ may harmonize to a greater extent, whereas those of GA and vitamin D may be more redundant. Indeed, if this theory were proven true, the observation that GA exerts a weaker effect on $\mathrm{Gd}+\mathrm{MRI}$ activity than $\mathrm{IFN}^{22,23}$ may explain why vitamin $\mathrm{D}$ had a greater relative impact on MRI vs clinical metrics in the GA-treated group. Another explanation for differences in efficacy across treatment groups may be that specific genetic alleles 
A

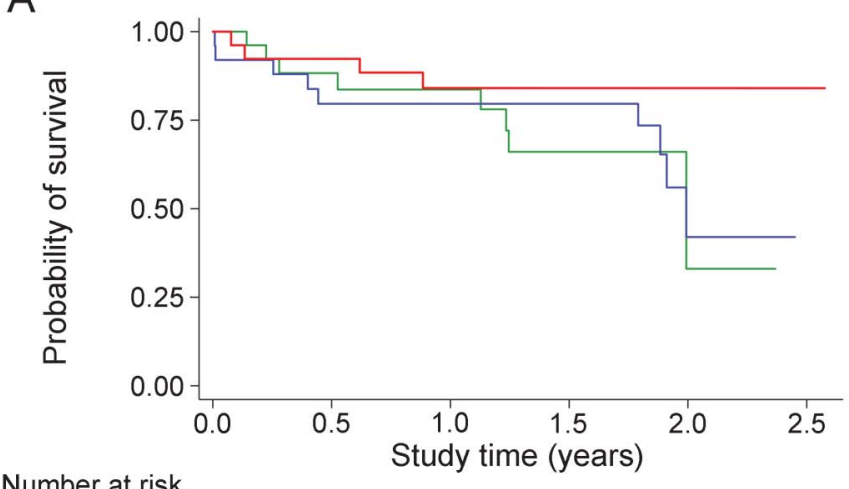

B

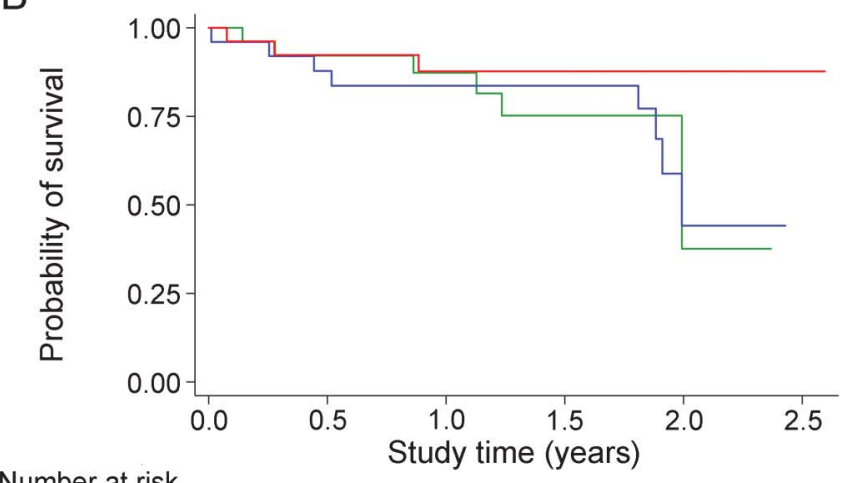

Number at risk

$\begin{array}{rllcll}\text { Bottom 26 } & 20 & 17 & 9 & 1 & 0 \\ \text { Middle 25 } & 21 & 18 & 15 & 3 & 0 \\ \text { Top 26 } & 24 & 18 & 15 & 6 & 2\end{array}$

$\mathrm{D}$

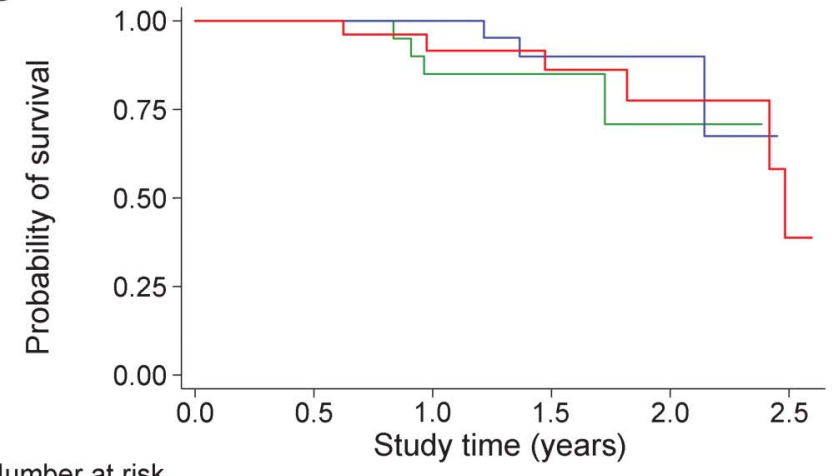

Number at risk

$\begin{array}{rlllll}\text { Bottom } 26 & 21 & 16 & 9 & 1 & 0 \\ \text { Middle } 25 & 24 & 22 & 15 & 5 & 0 \\ \text { Top 26 } & 26 & 20 & 16 & 5 & 2\end{array}$

In each graph, bottom tertile: solid line; middle tertile: long dashed line; top tertile: short dashed line. (A) Time to first inflammatory event (relapse or gadoliniumenhancing lesion). (B) Time to first relapse. (C) Time to first gadolinium-enhancing lesion. (D) Time to first Expanded Disability Status Scale progression.

modulate an interaction between vitamin $\mathrm{D}$ and some or all of the DMTs. These hypotheses about potential immunologic interactions between vitamin $\mathrm{D}$ and the DMTs warrant further investigation.

This study utilized a large, prospective cohort to explore the relationship between vitamin D status and disease activity. Other strengths of this study include the availability of $225(\mathrm{OH}) \mathrm{D}$ measurements for the majority of participants and the prolonged follow-up times, particularly in the IFN/GA cohort. However, it would have been ideal to access regular 25(OH)D measurements throughout follow-up. Using the average of 2 vitamin D measurements allows for a better estimate of the underlying vitamin $\mathrm{D}$ level, although in a minority of cases the second $25(\mathrm{OH}) \mathrm{D}$ measurement followed the outcome, which is a limitation. Other limitations of this work emerged from difficulty in timing the initial investigations with DMT initiation in the first-line treatment cohort. The FTY cohort allowed for a unique opportunity to obtain blood samples on the day of treatment start because of the mandated first-dose observation. Practically, we could not consistently acquire blood draws on the day of GA or IFN treatment start; we thus counted the first blood draw after treatment start as our baseline time point, but there was variability in when this occurred relative to treatment onset, although all baseline samples were obtained within 18 months. Likewise, it was difficult to investigate T2 lesions as an outcome measure because we could not determine whether a new T2 lesion on the first MRI study after the initial blood draw had occurred prior to treatment start as well. In contrast, $\mathrm{Gd}+$ lesions generally develop within 30 days of the study date in question, providing increased assurance that the outcome followed the baseline vitamin D measurement. Finally, a linear impact of $25(\mathrm{OH}) \mathrm{D}$ levels was observed when the 3 participants with the highest $25(\mathrm{OH}) \mathrm{D}$ levels were removed. Future studies with a larger number of participants must investigate the potential nonlinear impact of very high $25(\mathrm{OH}) \mathrm{D}$ levels. 
We attempted to control for evolution in vitamin D supplementation rates during the study period, although this analysis must be interpreted with caution because these data were not collected prospectively and compliance was not routinely elicited by clinicians. Nevertheless, by utilizing 25(OH)D level as the exposure measure, the overall analysis already takes the effect of vitamin D supplementation into account. The results for progression should also be interpreted with caution; we used nonsustained progression given the limited follow-up times, but this may be a surrogate for relapses. A final limitation of this analysis is that our findings cannot be generalized to patients of diverse ethnic backgrounds, given the preponderance of Caucasians in this cohort.

This study raises the possibility of whether DMT class may modify the effect of vitamin $\mathrm{D}$ on disease activity in MS. These findings need to be replicated in other cohorts, ideally in the setting of randomized controlled trials, and the effect of vitamin D needs to be explored with respect to other DMTs, such as natalizumab and dimethyl fumarate. Evidence of synergy between vitamin D and certain DMTs could be important in developing personalized approaches to MS therapy. The immunologic and genetic underpinnings of these relationships should be explored, as they will become of increasing relevance as we move towards therapeutic strategies targeting multiple mechanisms of action. Vitamin D supplementation is a low-cost, low-risk intervention that may potentiate the efficacy of certain DMTs against MS, without the risk of abetting serious adverse events as posed by other combination therapies.

\section{AUTHOR CONTRIBUTIONS}

Dr. Rotstein contributed to the overall study design and concept, acquisition of data, data analysis and interpretation, and the design and drafting of the intellectual content of this manuscript. Dr. Healy contributed to the design and statistical analysis and drafting for the intellectual content of this manuscript. Dr. Malik contributed to the intellectual content of this manuscript and acquisition of data. Dr. Carruthers contributed to the intellectual content of this manuscript and acquisition of data. A.J. Musallam contributed to the statistical analysis and drafting of the intellectual content of this manuscript. Dr. Kivisakk contributed to the intellectual content of this manuscript and acquisition of data. Dr. Weiner contributed to the intellectual content of this manuscript. Dr. Glanz contributed to the intellectual content of this manuscript and acquisition of data. Dr. Chitnis contributed to the overall study design and concept, data analysis and interpretation, drafting of the intellectual contents of this manuscript, and overall study supervision and funding.

\section{ACKNOWLEDGMENT}

D.L.R. received a Fellowship Training Grant from the MS Society of Canada. R.L.C. received a Clinical Fellowship Training Grant from the National Multiple Sclerosis Society. The authors thank the patients participating in the CLIMB study for their contributions to MS research and to Mariann Polgar-Turcsanyi, MS, for her role in managing the Partners MS Center research database. This work was conducted with support from Harvard Catalyst/The Harvard Clinical and Translational Science Center (National Center for Research Resources and the National Center for Advancing Translational Sciences, NIH Award 8UL1TR000170-05, and financial contributions from Harvard University and its affiliated academic health care centers). The content is solely the responsibility of the authors and does not necessarily represent the official views of Harvard Catalyst, Harvard University and its affiliated academic health care centers, or the NIH.

\section{STUDY FUNDING}

Supported by the National Multiple Sclerosis Society RG-4256A4/2 (T.C.). The CLIMB study is funded in part by the Nancy Davis Foundation and Merck Serono S.A. This work was conducted with support from Harvard Catalyst/The Harvard Clinical and Translational Science Center (National Center for Research Resources and the National Center for Advancing Translational Sciences, NIH Award 8UL1TR000170-05, and financial contributions from Harvard University and its affiliated academic health care centers).

\section{DISCLOSURE}

D.L. Rotstein received speaker honoraria from Sanofi and Novartis, has consulted for Sanofi, and received research support from Biogen and MS Society of Canada. B.C. Healy is on the editorial board for Statistical Methods in Medical Research and received research support from Merck Serono, Novartis, Genzyme, NIH, and National Multiple Sclerosis Society. M.T.A. Malik received research support from Merck-Serono and National Multiple Sclerosis Society. R.L. Carruthers received speaker honoraria from Genzyme, Biogen, and Teva. A.J. Musallam reports no disclosures. P. Kivisakk received research support from EMD Serono. H.L. Weiner served on the scientific advisory board for The Guthy Jackson Charitable Foundation, Teva Pharmaceuticals, Biogen Idec, Novartis, and Sanofi-Aventis, has consulted for Therapix, Biogen, Novartis, Serono, Teva, and Sanofi, and received research support from EMD Serono, NIH, and National Multiple Sclerosis Society. B.I. Glanz received research support from Merck-Serono, NIH, and NMSS. T. Chitnis served on the clinical trial advisory board for Novartis and Genzyme-Sanofi, has consulted for Biogen Idec, Novartis, Merck-Serono, and Alexion, and received research support from EMD-Serono, Novartis, National Multiple Sclerosis Society, Peabody Foundation, Consortium for MS Centers, and Guthy Jackson Charitable Foundation. Go to Neurology.org/nn for full disclosure forms.

Received June 18, 2015. Accepted in final form September 11, 2015.

\section{REFERENCES}

1. Ascherio A, Munger KL, Simon KC. Vitamin D and multiple sclerosis. Lancet Neurol 2010;9:599-612.

2. Munger KL, Levin LI, Hollis BW, Howard NS, Ascherio A. Serum 25-hydroxyvitamin D levels and risk of multiple sclerosis. JAMA 2006;296:2832-2838.

3. Munger KL, Zhang SM, O'Reilly E, et al. Vitamin D intake and incidence of multiple sclerosis. Neurology 2004;62:60-65.

4. Simpson S Jr, Taylor B, Blizzard L, et al. Higher 25hydroxyvitamin D is associated with lower relapse risk in multiple sclerosis. Ann Neurol 2010;68:193-203.

5. Ascherio A, Munger KL, White R, et al. Vitamin D as an early predictor of multiple sclerosis activity and progression. JAMA Neurol 2014;71:306-314.

6. Mowry EM, Krupp LB, Milazzo M, et al. Vitamin D status is associated with relapse rate in pediatric-onset multiple sclerosis. Ann Neurol 2010;67:618-624.

7. Runia TF, Hop WC, de Rijke YB, Buljevac D, Hintzen RQ. Lower serum vitamin D levels are associated with a higher relapse risk in multiple sclerosis. Neurology 2012;79:261-266.

8. Mora JR, Iwata M, von Andrian UH. Vitamin effects on the immune system: vitamins A and D take centre stage. Nat Rev Immunol 2008;8:685-698.

9. Correale J, Ysrraelit MC, Gaitan MI. Immunomodulatory effects of vitamin D in multiple sclerosis. Brain 2009;132: $1146-1160$. 
10. Stewart N, Simpson S Jr, van der Mei I, et al. Interferonbeta and serum 25-hydroxyvitamin D interact to modulate relapse risk in MS. Neurology 2012;79:254-260.

11. Loken-Amsrud KI, Holmoy T, Bakke SJ, et al. Vitamin D and disease activity in multiple sclerosis before and during interferon-beta treatment. Neurology 2012;79:267-273.

12. Soilu-Hanninen M, Aivo J, Lindstrom BM, et al. A randomised, double blind, placebo controlled trial with vitamin D3 as an add on treatment to interferon beta-1b in patients with multiple sclerosis. J Neurol Neurosurg Psychiatry 2012;83:565-571.

13. Mowry EM, Waubant E, McCulloch CE, et al. Vitamin D status predicts new brain magnetic resonance imaging activity in multiple sclerosis. Ann Neurol 2012;72: 234-240.

14. Gauthier SA, Glanz BI, Mandel M, Weiner HL. A model for the comprehensive investigation of a chronic autoimmune disease: the multiple sclerosis CLIMB study. Autoimmun Rev 2006;5:532-536.

15. Polman $\mathrm{CH}$, Reingold SC, Edan G, et al. Diagnostic criteria for multiple sclerosis: 2005 revisions to the “McDonald Criteria." Ann Neurol 2005;58:840-846.

16. Gorman MP, Healy BC, Polgar-Turcsanyi M, Chitnis T. Increased relapse rate in pediatric-onset compared with adult-onset multiple sclerosis. Arch Neurol 2009;66: 54-59.
17. Kappos L, Radue EW, O'Connor P, et al. A placebocontrolled trial of oral fingolimod in relapsing multiple sclerosis. N Engl J Med 2010;362:387-401.

18. Bhargava P, Steele S, Cassard S, et al. The Vitamin D to Ameliorate Multiple Sclerosis (VIDAMS) trial. Neurology 2014;82(suppl 10):P3.191.

19. Correale J, Ysrraelit MC, Gaitan MI. Vitamin D-mediated immune regulation in multiple sclerosis. J Neurol Sci 2011;311:23-31.

20. Smolders J, Thewissen M, Peelen E, et al. Vitamin D status is positively correlated with regulatory $\mathrm{T}$ cell function in patients with multiple sclerosis. PLoS One 2009; 4: e6635.

21. Farias AS, Spagnol GS, Bordeaux-Rego P, et al. Vitamin D3 induces IDO + tolerogenic DCs and enhances Treg, reducing the severity of EAE. CNS Neurosci Ther 2013; 19:269-277.

22. Cohen JA, Barkhof F, Comi G, et al. Oral fingolimod or intramuscular interferon for relapsing multiple sclerosis. N Engl J Med 2010;362:402-415.

23. Yong VW. Differential mechanisms of action of interferon-beta and glatiramer acetate in MS. Neurology 2002;59:802-808.

24. Dhib-Jalbut S. Mechanisms of action of interferons and glatiramer acetate in multiple sclerosis. Neurology 2002; 58:S3-S9. 


\section{Neurology \\ Neuroimmunology \& Neuroinflammation}

Effect of vitamin D on MS activity by disease-modifying therapy class

Dalia L. Rotstein, Brian C. Healy, Muhammad T. Malik, et al.

Neurol Neuroimmunol Neuroinflamm 2015;2;

DOI 10.1212/NXI.0000000000000167

This information is current as of October 29, 2015

Updated Information \&
Services
Supplementary Material
References
Citations
Subspecialty Collections
Permissions \& Licensing
Reprints

Updated Information \& including high resolution figures, can be found at: http://nn.neurology.org/content/2/6/e167.full.html

Supplementary material can be found at: http://nn.neurology.org/content/suppl/2015/10/29/2.6.e167.DC1

This article cites 24 articles, 1 of which you can access for free at: http://nn.neurology.org/content/2/6/e167.full.html\#\#ref-list-1

This article has been cited by 2 HighWire-hosted articles: http://nn.neurology.org/content/2/6/e167.full.html\#\#otherarticles

This article, along with others on similar topics, appears in the following collection(s):

Multiple sclerosis

http://nn.neurology.org//cgi/collection/multiple_sclerosis

Information about reproducing this article in parts (figures,tables) or in its entirety can be found online at:

http://nn.neurology.org/misc/about.xhtml\#permissions

Information about ordering reprints can be found online: http://nn.neurology.org/misc/addir.xhtml\#reprintsus

Neurol Neuroimmunol Neuroinflamm is an official journal of the American Academy of Neurology.

Published since April 2014, it is an open-access, online-only, continuous publication journal. Copyright $\odot$ 2015 American Academy of Neurology. All rights reserved. Online ISSN: 2332-7812.

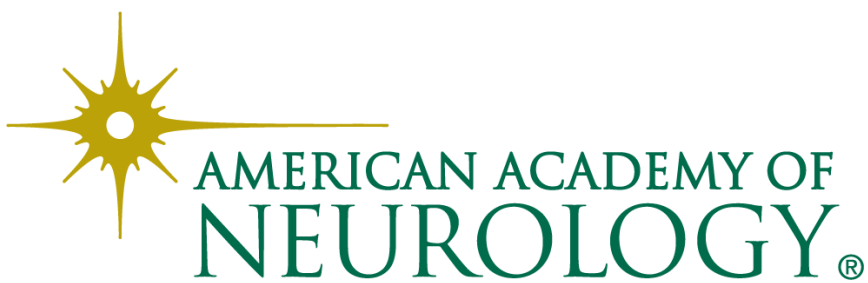

